\title{
点评2016版谷歌学术h5指数: 能否取代SCl评分体系?
}

\author{
Dr. Mike Wang
}

谷歌学术 (Google Scholar) 自 2012 年推出谷歌学术计量 (Google Scholar Metrics, GSM) 评价系统以来, 每年都发布谷 歌学术指数的报告。2016 年的 GSM 报告于 7 月 15 日发布。笔者 在之前分析的基础上继续对 2016 版 GSM 报告中各出版物的学术 指数进行分析点评。

\section{一、2016版谷歌学术计量报 告介绍}

该报告所收录的出版物需要 满足如下标准, 即: 2011-2015 年 5 年内发表至少 100 篇文章并且 至少有一个引用。该报告给出每 一出版物 3 方面的数据: $\mathrm{h} 5$ 指数 (h5-index)、h5 核心 (h5-core) 和 h5 中值 (h5-median)。这里提及的
“出版物” 不单单包括期刊, 还 包括计算机和电子工程学科内的 会议论文集以及论文预印本电子 数据库, 这一点与 Science Citation Index (SCI) 评价体系中的《期 刊引证报告 (JCR)》中只收录期 刊不同。

2016 版 GSM 报告中对 7398 份出版物进行了引用分析, 其中 有 1665 份出版物 (22.5\%) 至少 在两类不同领域排名中重复出 现，因此该报告中实际上只分析 了 5734 份出版物。与 2015 年报 告中提供了 9 种不同语言 (英语、 中文、葡萄牙语、德语、西班牙 语、法语、意大利语、日语、荷 兰语）出版物的前 100 名的信息 相比， 2016 年的报告中提供了 12 种 (英语、中文、葡萄牙语、德 语、西班牙语、俄语、法语、日语、
韩语、波兰语、乌克兰语、印度 尼西亚语）不同语言出版物的前 100 名的信息，其中俄语、韩语、 波兰语、乌克兰语、印度尼西亚 语这五种是新增的, 不过没有了 意大利语和荷兰语两种语言方面 的出版物信息。

该报告对八大领域的 262 类 学科出版物进行引用排名分析, 其中化学与材料科学领域中的 Corrosion 学科内的出版物没有被 收录在内。新版本中去掉了较多 的 “Working Papers 和 Discussion Papers” 系列, 比如在 2015 年 Top100 的 CEPR Discussion Papers 在新的版本中就找不到。

\section{二、英文出版物Top20分析}

2016 年 Top20 出版物包含 19

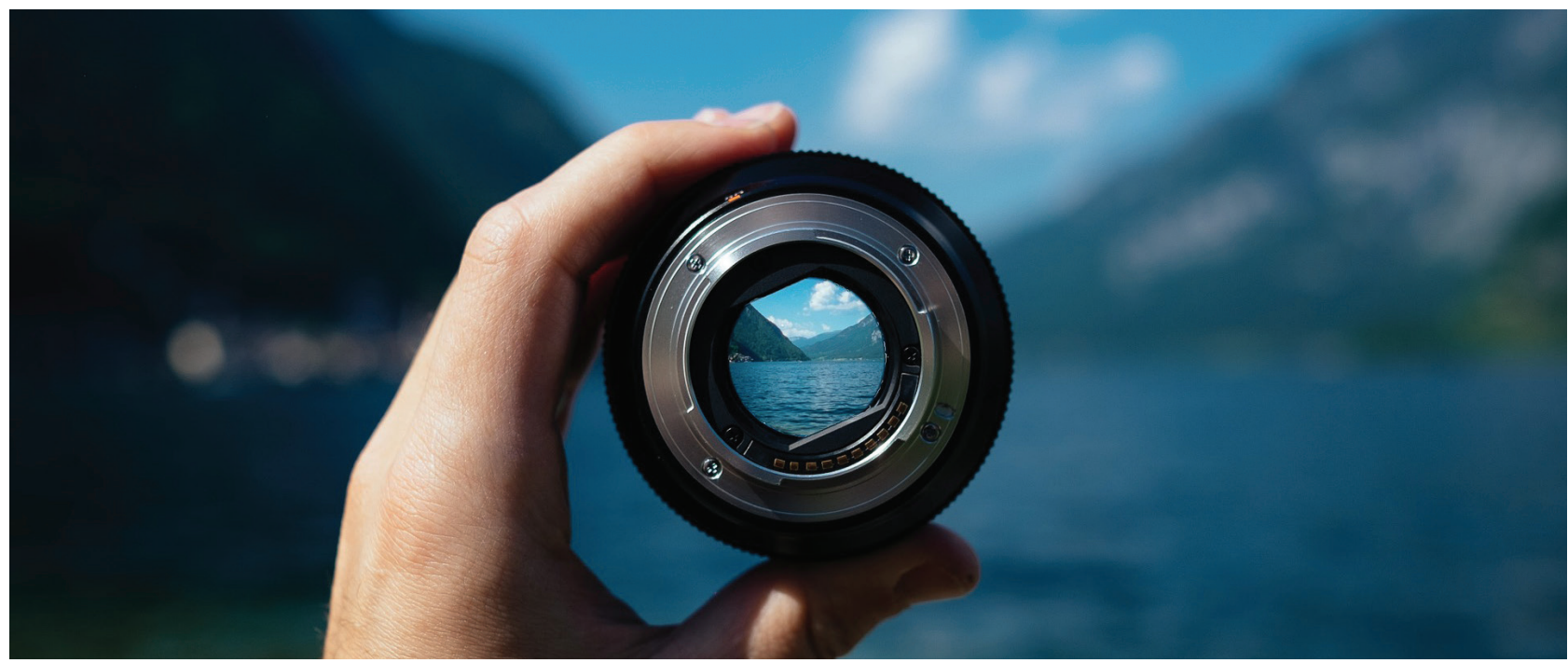




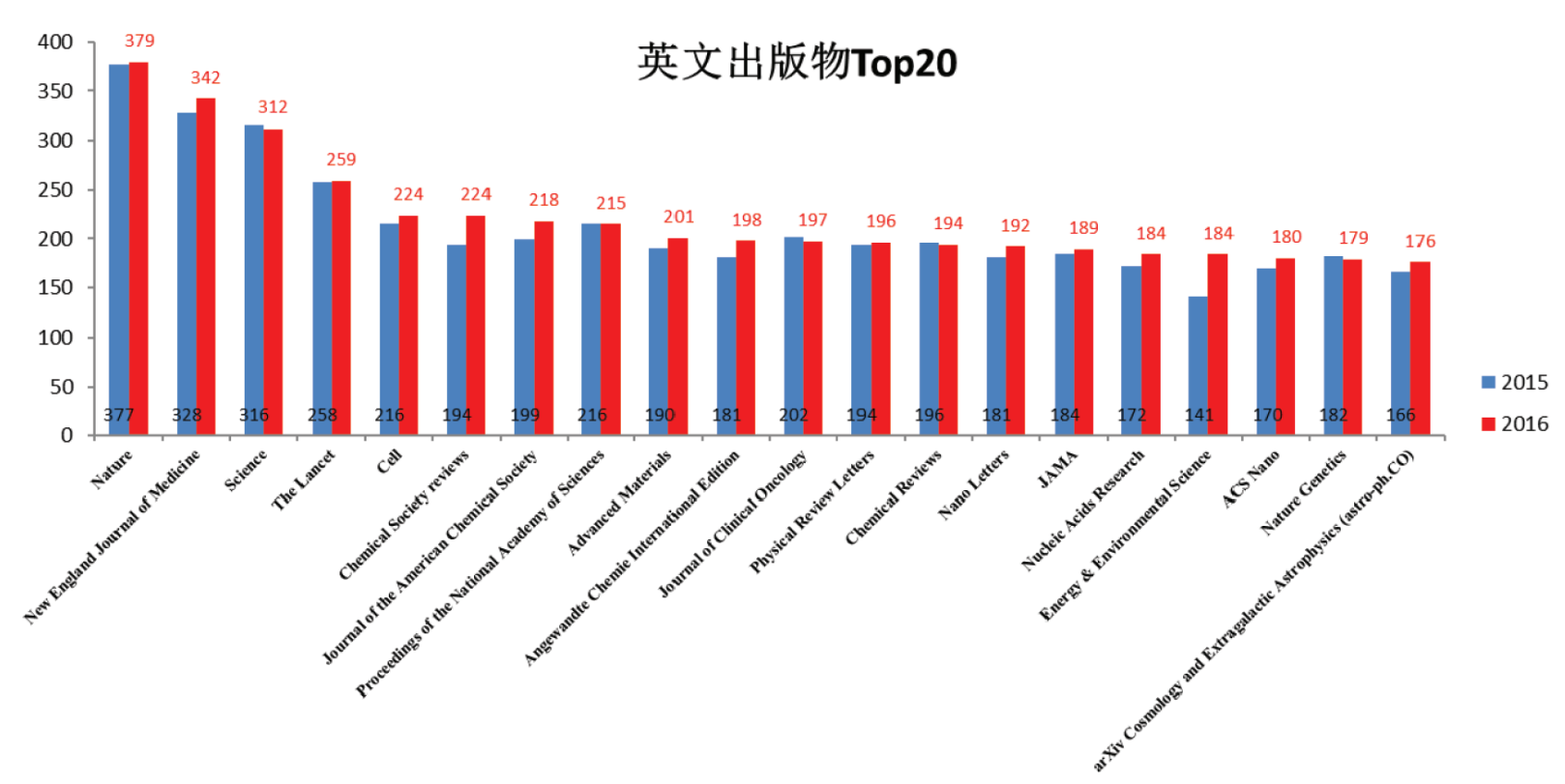

\section{图1.2016版CSM报告中英文出版物Top20的H5指数}

份期刊和 1 个论文预印本电子数 据库。与 2015 年相比, 2016 年 仍然有 19 份出版物是排在 Top20 之中。唯一的 “黑马” 期刊 Energy \& Environmental Science 从 2015 年的 34 名挤进 Top20 的第 17 位, 其 h5 指数从 2015 年的 141 上升到 2016 年的 184 , 增加 了 43 (图 1)。

2016 年排在前五名的期刊 包括了 CNS、新英格兰医学杂志 以及柳叶刀杂志。这五份期刊排 名依次为 Nature、New England Journal of Medicine, Science、 Lancet 和 Cell, 与 2015 年排名相 比没有变化, 它们的 h5 指数分别 是 379、342、312、259、224 (图 1)。

2016 年排名第 20 位的是论 文预印本电子数据库 (arXiv Cosmology and Extragalactic Astrophysics (astro-ph.CO)), h5 指数 是 176, 比 2015 年增加了 10 , 但 是排名位次没有变化。

其余 13 份期刊分别为 Chemical Society reviews、Journal of the American Chemical Society Proceedings of the National Academy of Sciences, Advanced Materials、Angewandte Chemie International Edition、 Journal of Clinical Oncology, Physical Review Letters、Chemical Reviews、 Nano Letters、JAMA、Nucleic Acids Research、ACS Nano、Nature Genetics, 分别排名为 6-16 和 18-19; 其中排名上升最大的是 Angewandte Chemie International Edition, 上升了 7 位, 其 $\mathrm{h} 5$ 指数 为 198 , 比 2016 年增加了 17 ; 而 h5 指数增加最多的期刊是 Chemical Society reviews, 从 2015 年 的 194 增加到 2016 年的 224, 排 名从 2015 年的第 10 位升到 2016 年的第 6 位 (图 1)。

\section{三、中文出版物Top20分析}

中文 Top20 中的 20 份出版 物都是期刊。与 2015 年相比,
2016 年 Top20 中有 18 份期刊也 在 2015 年的 Top20 中、且排名 浮动不大; 其中 $\mathrm{h} 5$ 指数降低的期 刊有 13 份, 降低最多的是排在第 1 和 6 位的《经济研究》和《中华 医院感染学杂志》, 分别从 2015 年的 57 和 46 降到 2016 年的 49 和 38。两份新冲进 Top20 的期刊 是《护士进修杂志》和《计算机 学报》, 分别从 2015 年排名第 27 位和 24 位上升到 2016 年的第 16 和 18 位, 它们 2016 年的 h5 指数分别为 33 和 31 。排在 2015 年 Top20 第 18 位的《电力系统保 护与控制》排在 2016 年的第 25 位, 其 h5 指数从 2015 年 33 降 到 2016 年的 29。另一份被挤出 Top20 的期刊是《地球与环境》, 2015 年排在第 20 位。2016 年甚 至没有排到 Top100 之中, 但是 还是能查到它的 $\mathrm{h} 5$ 指数, 为 37 。 若按其 $\mathrm{h} 5$ 的数值应该排在中文 期刊的前十, 但是不知道为什么 没有被收录到 Top100 之中, 到底 


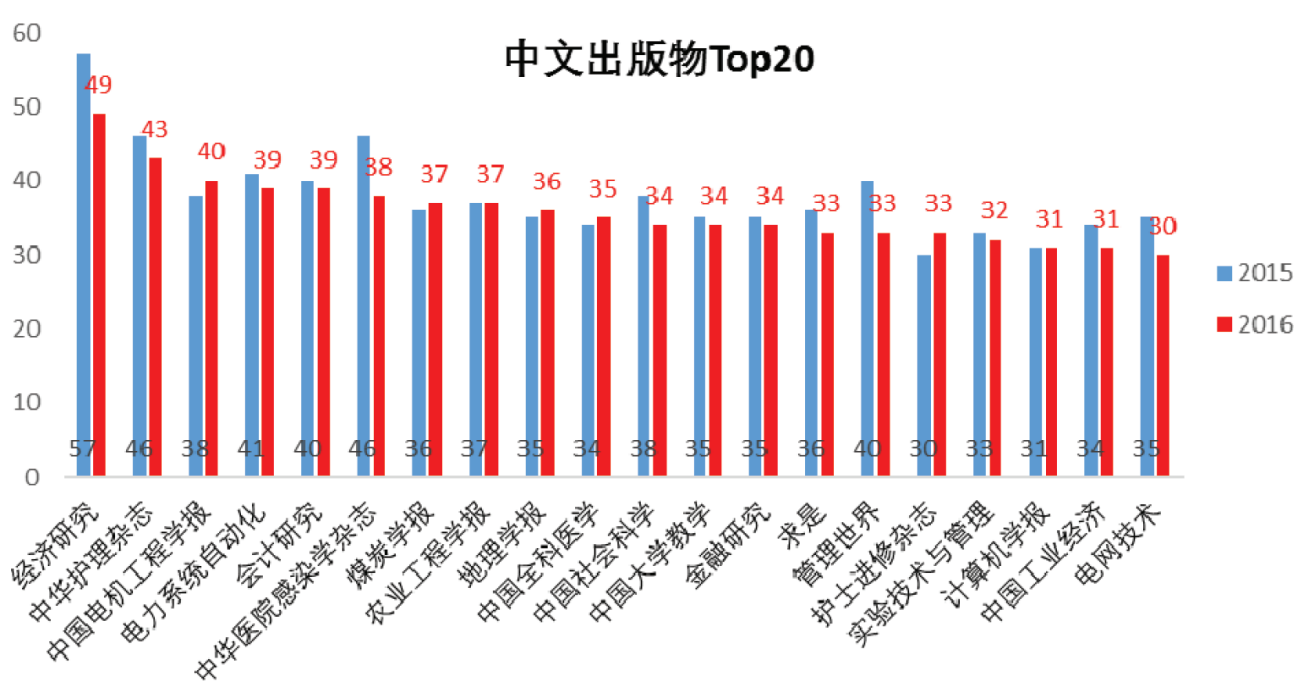

\section{图2.2016版GSM报告中中文出版物Top20的H5指数}

是谷歌学术的错误、还是该杂志 没有满足五年内发表 100 篇文章 的要求? 原因未知。

\section{四、谷歌学术计量报告亟待 改进之处}

在 SCI 评价体系被众人诟病 的今天, GSM 体系的出现必然有 其合理性。其优点包括免费查询、 有对多种语言出版物的评估、不 受单篇或少数论文超高引用的影 响、及数据库收入范围广等。但 作为新生事物, GSM 报告也有许 多地方需要改进, 比如:

1. 不够透明: 该报告没有提供 谷歌学术旗下的出版物的总 数、主办国家及语言。

2. 数据不够完整、全面:

1) GSM 没有给出每一收录出 版物的论文发表总数以及 过去五年内的论文发表数;

2) 谷歌学术应该不单单是给 出 h5 论文的引用信息, 而 是给出每一收录出版物的 所有论文引用信息;
3) 谷歌学术没有给出所收录 的会议及电子数据库的列 表。

3. 分类标准不明确: 未能给出 GSM 对领域及学科的分类标 准。

4. 没有向公众公开过去几年 GSM 报告（2007-2011, 20082012, 2009-2013, 2010-2014)。 笔者个人认为并非谷歌学术 不想公开，而是技术和费用 的要求都比较高, 毕竟有那么 多出版物及文章; 且 GSM 报 告还未商业化, 不知谷歌是 否打算投钱在这上面。

5. 目前没有提供 “语言”、“国 家”及“学科”作为关键词 来对数据库进行搜索的功能。

6. 有查询限制。目前谷歌学术只 允许查询不同语言的 Top100 出版物信息和每一学科的 Top20。如果要放开所有出 版物和学科查询限制, 那么, 同样需要强大的技术和资金 支持。

综上, GSM 指标的出现,
为科研界提供了除影响因子外的 另一个期刊或出版物影响力评价 的参考。有的杂志甚至已经把谷 歌学术指标与 SCI 影响因子一起 放到自己的官网。但与有强大技 术和财力支持、且商业化的 JCR 相比, GSM 指标目前远未成熟, 只能作为参考。

世界本来就应该是多彩的, 笔者十分期待 GSM 指标能够进 一步完善，也期待有其它更客观、 更实用的期刊或出版物评价体系 出现。

\section{参考文献}

[1] Google Scholar Metrics. (2016) Retrieved July 22, 2016, from https:// scholar.google.com/intl/zh-TW/ scholar/metrics.html\#overview.

[2] Mike. 美捷登精彩点评: 谷歌学术 H5 指数及其与汤森路透影响因子 对比分析. http://blog.sciencenet.cn/ blog-475824-910701.html.

[3] Martín-Martín A, Ayllón J.M., Orduna-Malea E., Delgado López-Cózar E. (2016). 2016 Google Scholar Metrics released: a matter of languages... and something else. EC3 Working Papers, 22. 21st of July 2016. 